\title{
RAÇA, BRANQUITUDE E DESCOLONIZAÇÃO: O TRABALHO DE GRADA KILOMBA
}

JULIA LANDGRAF ${ }^{1}$

UFRGS, BRASIL

\section{RESENHA}

KILOMBA, Grada. Memórias da plantação: episódios de racismo cotidiano. Rio de Janeiro: Cobogó, 2019.

Grada Kilomba nasceu em Lisboa, com origens em Angola e São Tomé e Príncipe. A teórica, reconhecida também por seu trabalho artístico interdisciplinar, estudou psicologia e psicanálise em sua cidade de nascimento. Ao deixar Portugal, onde foi a única estudante negra de seu departamento e sofreu com o racismo ao longo de seus anos de prática profissional, encontrou em Berlim a proeminência de uma frutífera corrente de intelectuais negras como Audre Lorde, Angela Davis, May Ayim e Du Bois, que muito impactaram seu trabalho. Recebeu uma das mais importantes bolsas do governo alemão para a realização de seu doutorado, trabalho pelo qual ganhou "a mais alta (e rara) distinção acadêmica" (p.11). Deu aula na Universidade de Humboldt e na Freie Universität, principalmente sobre o trabalho de Franz Fanon e bell hooks.

Sua tese de doutoramento, transformada no livro de título "Memórias da plantação: episódios de racismo cotidiano", fala a partir da teoria pós-colonial, psicanálise, estudos de gênero e do feminismo negro. Levou dez anos para chegar traduzida ao Brasil e a Portugal - Kilomba refere que a romantização de discursos coloniais e patriarcais não permitiu que isso ocorresse antes (p.13), o que aponta para a relevância da disseminação de seu trabalho.

A estrutura do livro conta com quatorze capítulos, sendo os quatro primeiros teóricos, a respeito do colonialismo, trauma, descolonização e da conceituação do racismo, além de problematizar a ideia de quem pode falar, através do processo do subalterno deixar de ser objeto para passar a ser sujeito. Os capítulos seguintes tematizam o racismo cotidiano a

\footnotetext{
${ }^{1}$ Mestranda em Antropologia Social (Universidade Federal do Rio Grande do Sul, Brasil). E-mail: ferneda.julia@gmail.com
} 
partir de extratos de duas entrevistas conduzidas pela autora para a realização de sua pesquisa.

Kilomba refere-se à "máscara do silenciamento", objeto colonial europeu utilizado para impedir escravizados de comer e falar, como um instrumento que se perpetua até hoje de forma subjetiva, representando o colonialismo, que define quem tem voz - questão problematizada por Spivak (1995) também por um viés colonial ao apontar que a voz das subalternas ${ }^{2}$ não é ouvida pelos que detém o poder. Na academia, isso se perpetua pelo mito de uma "objetividade" e "neutralidade"3 que são, na verdade, profundamente subjetivas, operando em prol dos interesses e problemas da classe dominante branca, e assim o colonialismo configura a produção do conhecimento. A invalidação do conhecimento produzido de forma localizada por essas subalternas, para Kilomba, relaciona-se com a ideia de que o oprimido está vendo algo que não deve ser visto, algo que revelaria "um segredo". Seu pensamento é congruente com o conceito de Maria Aparecida Silva Bento (2002) de "pacto narcísico", um acordo branco na sociedade brasileira de não falar sobre o racismo, encarando a desigualdade racial como um problema do negro: culpandoo, reafirma-se a ideia de merecimento do lugar social que ambos os grupos ocupam (a dominância dos brancos e a subalternidade dos negros). Assim, o "segredo" não é revelado.

Entrevistando mulheres de grupos sociais similares ao seu, Kilomba rejeita o suposto "distanciamento" e "neutralidade" para o fazer pesquisa e retira essas mulheres de um lugar de objeto enquanto "Outras", criando um espaço para a performatividade de suas subjetividades ao reconhecêlas enquanto sujeitos da sociedade. As entrevistas são parte do projeto de "entender, reconstruir e recuperar a experiência de mulheres negras com o racismo em uma sociedade branca patriarcal" (p.81), considerando o gênero também como marcador nessas experiências. Duas entrevistas baseadas nas narrativas biográficas das entrevistadas foram analisadas, conformando as temáticas dos capítulos quatro a treze: a de Alicia, mulher afro-alemã de 33 anos, e a de Kathleen, mulher afroestadunidense que vive na Alemanha, de 27 anos. Os conceitos e episódios trazidos a seguir não pretendem de forma alguma esgotar a riqueza teórica do trabalho de Grada Kilomba, mas sim pontuar o que me parece especialmente frutífero para pensar o cenário brasileiro de estudos etnicorraciais e da branquitude.

O racismo é definido em "Memórias da plantação" através de três características principais: a construção da diferença, através da qual o branco se autointitula como "norma" e, então, o "Outro" não-branco passa a ser visto como diferente; a hierarquização dessa diferença a partir da naturalização de uma suposta inferioridade negra, tendo como

\footnotetext{
${ }^{2}$ Grada Kilomba opta por adotar a tradução do termo (sem gênero em inglês) no feminino por considerar problemático reduzi-lo ao gênero masculino, considerando que Spivak trabalhou com a crítica de gênero e "revolucionou os movimentos feministas com a sua escrita" (p.20). A opção pelo grifo em itálico deste termo e de outros utilizados nessa resenha é de Kilomba, e foi respeitada nesta publicação.

${ }^{3}$ A autora desta resenha se localiza aqui enquanto mulher e branca, assinalando estes demarcadores sociais enquanto forma de reconhecer sua fala a partir de um local de produção de conhecimento possível, e não de uma suposta neutralidade universal do sujeito branco.
} 
consequência o preconceito (do "diferente inferior"); e o poder histórico, político, social e econômico dessa "classe" branca dominante (essa manutenção das pessoas negras fora das estruturas de poder é denominada racismo estrutural, enquanto o racismo institucional é referente ao desigual tratamento das pessoas baseado na raça na educação, mercado de trabalho, etc). Ao abordar neste trabalho "episódios de racismo cotidiano", Grada Kilomba não se refere a experiências pontuais de preconceito, mas ao padrão contínuo de violência a qual pessoas negras são expostas ao serem colocadas como "Outra" ao invés de "eu"; esses episódios se repetem "incessantemente ao longo da biografia de alguém - no ônibus, no supermercado, em uma festa, no jantar, na família" (p.80).

A branquitude, então, define-se como norma e ponto de referência para todos os "Outros" que dela diferem, projetando (em termos freudianos) nestes tudo aquilo que sua sociedade tornou tabu e reprimiu, como a "agressão" e a "sexualidade", percebendo os negros enquanto incivilizados, selvagens, animalizados, exóticos e erotizados. Assim, apesar de seu histórico de opressão, a branquitude se coloca enquanto "civilizada", em oposição a tudo aquilo que projetou no outro. O racismo é uma construção branca a nível estrutural e institucional, vivido por pessoas negras e outras subalternidades, como os povos indígenas. A tendência de patologizar o racismo enquanto "problema do negro" exime as pessoas brancas da responsabilidade de ouvir verdades inconvenientes - que, quando levadas com responsabilidade, permitiriam retirar o branco de seu lugar de poder e privilégio - mantendo, assim, o "pacto narcísico" (BENTO, 2002).

A autora chama de "constelação triangular do racismo" um funcionamento que permite que o racismo cotidiano seja cometido ao exemplificar com um episódio vivido por Kathleen com seu namorado branco, no qual ele conta para ela uma piada racista que havia sido compartilhada entre seu grupo de amigos brancos (p.135). O triângulo criado entre o ator que performa o racismo, o sujeito negro que se torna objeto do racismo (nesse caso, Kathleen, através do personagem negro da piada) e a platéia branca (os amigos do namorado), que observa e apoia o ato, reitera a posição de poder do namorado, protegido pelo seu grupo, com quem a piada foi compartilhada. Kathleen está sozinha frente a uma coletividade branca alienante, na medida em que é insultada sem ser o objeto direto do insulto: essa dupla inclusão-exclusão da pessoa negra presente torna o público branco confortável para essa performance do racismo.

A assimetria de poder do racismo permite que a branquitude defina fronteiras geográficas, marcos territoriais que operam a partir do organizador "raça", confinando os negros em espaços "inferiores", marginais. Essa segregação espacial se relaciona a outra faceta importante do racismo cotidiano, as fantasias de contágio racial. Kilomba exemplifica simbolicamente a separação desses dois mundos ao lembrar

\footnotetext{
${ }^{4}$ A construção da ideia de raça se articula e perpetua de maneira global uma dominação desde o século XVI. Dessa forma, é uma estrutura e um problema social que se refere a todos.
} 
"as luvas brancas que pessoas negras eram forçadas a usar ao tocar o mundo branco" (p.168), em contexto médico contra a "contaminação somática", relacionando a pele negra a algo inferior, sujo, infectado. Mary Douglas (1966) já havia esquematizado a limpeza e a sujeira enquanto pares dentro de sistemas de ordenação, esquema que serve para pensar a segregação territorial e o "contágio racial" quando negros são vistos enquanto sujos ao atravessar as fronteiras que os situam nas margens, em espaços onde poderiam "tocar" os privilégios brancos.

Como já deve ter sido percebido, alguns termos chave desta resenha foram grifados em itálico. Na introdução escrita para a tradução em português da obra, a autora ressalta a origem colonial de muitos termos utilizados ainda na atualidade, sem uma reflexão histórica que permita a reinvenção de um vocabulário. Ela aponta a potência política da linguagem, que reafirma relações de poder e subalternidade, e define identidades. Assim ocorre com o uso da palavra negro/a, que mesmo positivada em um contexto brasileiro, ancora-se em uma terminologia colonial que remete "a uma história de violência e desumanização" (p.17), tendo sido usada para determinar a subordinação dos africanos para com a Europa. A reflexão e substituição dessa palavra (como ocorreu na Alemanha, de onde a autora fala) não foi feita na língua portuguesa, e para problematizá-la Kilomba opta por escrevê-la em itálico: negro/a. $\mathrm{O}$ capítulo nove, "A palavra $N$. e o trauma", traz um episódio vivido por Kathleen, de reencenação do passado colonial no presente através da utilização deste termo e o trauma disso decorrente.

Esta é uma importante chave para o trabalho da autora: a relação do trauma individual com o trauma colonial, isto é, a evocação de memórias coletivas coloniais através do trauma. O racismo cotidiano se apresenta como uma experiência traumática (a partir da ideia psicanalítica de trauma), que se configura através de três principais pontos: o choque violento, a separação/fragmentação e a atemporalidade. O choque violento é um acontecimento no qual não se encontra razão, uma agressão racista que remete ao cenário colonial, como quando Kathleen é chamada com os mesmos termos violentos da época da escravização. A irracionalidade do acontecimento impossibilita a compreensão cognitiva dessa experiência por quem a sofre, pois o racismo não fornece explicações "no plano da razão" (FANON, 2008). A separação é o sentimento de ruptura decorrente da violência do racismo cotidiano, que priva o sujeito de sua conexão com a sociedade. Perguntam a Alicia de onde ela é, e não aceitam sua resposta enquanto mulher alemã (p.111), rompendo sua noção de pertencimento. Essa fragmentação de quem ela é faz parte também da fragmentação histórica ocasionada pela escravização e pelo colonialismo. Por fim, a atemporalidade é revelada quando a pessoa negra é interpelada no presente como seria no passado, através de uma cena do racismo cotidiano que remete a uma época histórica colonial. É uma coexistência do passado com o presente, que segue colonizando.

Esse entrelaçamento do racismo com as cenas coloniais do passado é perpetuado de forma constante. À Kathleen lhe perguntavam de onde ela vinha, com o intuito de rastrear suas origens na África, o que a 
ofendia, pois não possuía meios de responder (p.179). Pessoas brancas questionam sobre sua história, quando Kathleen teve o conhecimento de sua ancestralidade negado exatamente pelas mesmas pessoas brancas, a partir da fantasia de que todos os seres humanos têm acesso à sua biografia histórica coletiva. Só é possível cogitar algo assim quando a história é esquecida - como se os recentes quatrocentos anos de escravização pudessem ser esquecidos. O sujeito branco vive um estado de "luto colonial" por não querer superar a perda do passado (do colonialismo e da supremacia branca), indignando-se com a possibilidade da pessoa negra se tornar igual a ele (p.226). "Esquecer" a história, não confrontar-se com ela, é uma maneira de manter as coisas como estão, evitando a criação de novas formas de poder e de conhecimento possíveis.

Grada Kilomba apresenta pontos chave para pensar a descolonização, o ato de desfazer-se do colonialismo. Ela utiliza parábolas para desenvolver uma analogia entre a conquista de territórios, a "extensão da soberania de um território para além de suas fronteiras", (p.225) e o contexto do racismo que, como no colonialismo, prende a pessoa negra em fantasias brancas do que ela deveria ser (p.224), em um processo de invasão no qual se tornam colônias metafóricas. Descolonizar seria, então, buscar independência e autonomia.

Uma das formas de fazer isso é sair da dependência colonial na qual o sujeito branco coloca o negro ao fazer com que este sempre se explique enquanto Outridade, definindo limites. Quando brancos demandam dos negros explicações sobre o racismo, não necessariamente seu desejo é entender, mas controlar: "o sujeito branco pergunta e o sujeito negro responde, o sujeito branco pede e o sujeito negro explica, o sujeito branco exige e o sujeito negro elucida" (p.228-229). Pessoas negras não têm a responsabilidade de educar pessoas brancas e nem de arcar com o trabalho emocional decorrente disso. O racismo não se dá por falta de informação, mas pelo desejo de poder sobre o outro. Ainda dentro dessa dinâmica, esse desejo de ser compreendido pela pessoa branca é uma diminuição dos sentimentos de raiva e angústia gerados pelo racismo. Esforçar-se o suficiente para explicar um ato de racismo não ocasionará um escape do racismo cotidiano, criando a ilusão de que existe uma "resposta perfeita" para este episódio, quando muitas vezes a única reação possível é o choque.

Grada Kilomba encerra descrevendo o processo de tornar-se sujeito da pessoa negra, consciente de sua negritude e do racismo cotidiano, através dos mecanismos de defesa do ego: negação (nega viver o racismo e assim se protege da ansiedade gerada por estas informações), frustração (gerada pela privação e incapacidade de atingir objetivos no mundo branco), ambivalência (sentimentos ambíguos com relação à pessoa branca, como confiança e desconfiança, nojo e esperança), identificação (com outras pessoas negras de forma positiva, afastando-se da "identificação alienante com a branquitude") (p.237), e, por fim, a 
descolonização, processo através do qual se deixa de existir enquanto "Outridade", para existir enquanto "eu", enquanto sujeito 5.

Pensando nos distintos cenários nacionais de estudo das temáticas etnicorraciais, evidenciam-se percursos distintos na conscientização e responsabilização pelo racismo. Se no prefácio da tradução de seu livro ao português Grada Kilomba aponta que Brasil e Portugal glorificavam sua história colonial, ela também contrasta este fato ao percurso alemão de responsabilização pelo passado recente, no qual a história nacional provocava culpa e vergonha. Independente da profundidade que tais processos assumem, é interessante pensar os impactos disso nos cenários acadêmicos nacionais. Se na Alemanha a maioria dos estudos sobre o racismo se foca nos agressores racistas e os membros dos partidos de extrema-direita, bem como no desenvolvimento de oficinas e programas para trabalhar com as pessoas que o perpetuam, o efeito colateral disso seria que "as vítimas reais do racismo [...] são rapidamente esquecidas" (p.72), perdendo importância enquanto sujeitos políticos. No Brasil, por muito tempo o cenário foi distinto, com a omissão da maior dos pesquisadores brancos da "escola paulista" ao tratar a raça exclusivamente como um problema do negro, mantendo o pacto narcísico ao não precisar olhar para si (BENTO, 2002). Se na sociedade alemã os membros de partidos neonazistas e de extrema direita fazem questão de expor seu racismo enquanto fator positivo para buscar uma "pureza" racial constituinte de um Estado-nação, tornando-se facilmente identificáveis, este processo se perpetua no Brasil de forma dissimulada através da ideologia do branqueamento e do ainda existente mito da democracia racial, o que se mostra num cenário acadêmico a partir de epistemologias também coloniais ${ }^{7}$.

O processo de descolonização permite que sejam criados novos papéis fora da ordem colonial, pois "ser contra" o discurso dominante do racismo não é suficiente (p. 69) - algo que foi dito extensivamente por pessoas negras como Malcom X, bell hooks, Angela Davis e Sueli Carneiro, para citar algumas. Aproximando então de um exemplo no cenário brasileiro, Lélia Gonzáles (1984) apresenta na abertura de seu texto o cenário de uma grande festa promovida por pessoas brancas que escreveram um livro sobre os negros: estes foram convidados para a

\footnotetext{
${ }^{5}$ Da mesma forma que a pessoa negra possui mecanismos de defesa do ego em relação ao racismo, operam mecanismos de defesa no sujeito branco que se torna consciente de sua branquitude e seu papel na perpetuação do racismo, que Kilomba sistematiza no capítulo 1 (p.43) a partir de um discurso público de Paul Gilroy. Estes artifícios do ego seriam: negação, culpa, vergonha, reconhecimento e reparação. Evidentemente, por serem etapas que demandam um intenso trabalho psicológico, o histórico branco de colocar-se como alheio ao racismo (como se este fosse um problema apenas das pessoas negras, com o qual pessoas brancas não possuem relação) aponta que grande parte das pessoas não chegará nas últimas etapas desse processo, nunca colocando-se como agentes de mudança das estruturas, relações e espaços que ocupam - dessa forma, perpetuando seus privilégios raciais.

${ }^{6}$ Pesquisadores da Universidade de São Paulo, ao redor da década de 50.

7 Assim como Kilomba faz uso do cenário pós-colonial para propor a "descolonização", fazendo uso de Fanon (que desde o século passado trabalhava com estes termos) como referência, a América Latina apresenta também caminhos para tais construções, como a teoria decolonial de Aníbal Quijano, entre outros autores. Ainda que a autora não trabalhe com esta referência, as parábolas por ela utilizadas para explicar a colonização enquanto conquista e dominação de corpos negros dialoga com o entendimento de Quijano da "colonialidade do poder".
} 
Espaço Ameríndio

festa, mas nunca puderam sentar-se junto aos brancos. Uma mulher negra reclama e arma-se a bagunça, gritos, vaias. As pessoas brancas ficam com raiva. Ainda que negros tenham sido convidados para a festa, os lugares ocupados por estas pessoas são os mesmos; o discurso situa a mulher negra da mesma forma; as pessoas que falam são as mesmas, discursando sobre um negro objeto, e não sujeito. Não basta convidar as pessoas negras para sentar na mesa se elas ainda serão servidas pelos mesmos. É necessário criar novas posições para estabelecer as relações, que prescindam da tão arraigada hierarquia racial. 
Espaço Ameríndio

\section{Referências Bibliográficas}

BENTO, Maria Aparecida Silva. Branqueamento e branquitude no Brasil. In: CARONE, Iray; BENTO, Maria Aparecida Silva (Orgs.). Psicologia social do racismo: estudos sobre branquitude e branqueamento no Brasil. Petrópolis: Vozes, 2002. p. 25-57.

DOUGLAS, Mary. Pureza e perigo. São Paulo: Perspectiva, 2014 [1966].

FANON, Frantz. Pele negra, máscaras brancas. Salvador: EDUFBA, 2008.

GONZÁLES, Lélia. Racismo e sexismo na sociedade brasileira. Revista Ciências Sociais Hoje, Anpocs, v.2, p.223-244, 1984.

SPIVAK, Gayatri Chakravarty. Pode o subalterno falar?. Belo Horizonte: UFMG, 2010.

Recebido em: 04/06/2020 * Aprovado em: 05/06/2020 * Publicado em: 11/09/2020 